\title{
STATE PAYMENTS TO VICTIMS OF VIOLENT CRIME: DISCRETION AND BIAS IN AWARDS FOR SEXUAL OFFENCES
}

Kathleen Daly and Robyn Holder

Corresponding author:

Kathleen Daly http://orcid.org/0000-0002-0530-0753

School of Criminology and Criminal Justice

Griffith University

Mt Gravatt Campus

176 Messines Ridge Road

Mt Gravatt QLD 4122

AUSTRALIA

k.daly@griffith.edu.au

tel: +61 (7) 3735-5625

fax: $+61(7) 3735-5608$

Robyn L. Holder http://orcid.org/0000-0002-1610-3544

Griffith Criminology Institute

Griffith University

Mt Gravatt Campus

176 Messines Ridge Road

Mt Gravatt QLD 4122

AUSTRALIA

\section{Abstract}

State monetary schemes for victims of violent crime began in the 1960s and operate in 35 countries today, yet knowledge is lacking on who is applying, how decisions are reached, variation in awards, and why amounts may differ. Analysing 291 sexual offence cases in Queensland, we ask whether awards differ by victim sex/gender and by societal constructs of ideal, real rape, and credible victims. We found that male child victims received higher awards than female child victims for more serious sexual offences, and that awards to females aged 12 and older were affected by elements associated with real rape and credible victims. We call upon researchers and governments to pursue and expand this new area of research.

British Journal of Criminology (forthcoming)

Please do not quote from or cite this ms. without permission of the senior author. 


\section{STATE PAYMENTS TO VICTIMS OF VIOLENT CRIME: DISCRETION AND BIAS IN AWARDS FOR SEXUAL OFFENCES}

\section{Introduction}

State schemes for criminal injuries compensation (CIC) or financial assistance (FA) to victims of violent crime emerged in the 1960s. ${ }^{1}$ Research has concentrated on scheme rationale, purpose, and legislative change (e.g., Ashworth 1986; Duff 1998; Miers 2014a, 2014b); scheme description and comparison (e.g., Barrett Meyering 2010; Davies 1991; Freckelton 2001; Miers 2014a; Thomson Reuters Foundation 2015); and victims' experiences and judgments (e.g., CASA House 1997; Mulder 2013; Smith and Galey 2018; see Holder and Daly 2018 for review). Few studies have analysed in detail what victims have received and whether there is variation in awards. Government reports and some studies provide aggregate average payments, at times by type of offence (Newmark et al. 2003; Salmelainen 1993; Office of Justice Programs 2015), but they do not analyse whether payments vary by applicant sub-groups, and if so, why. We lack knowledge on who is applying, how decisions are reached, variation in awards, and why amounts may differ. Conceptually, we lack a framework for understanding and explaining the impact of decision-makers' discretion and bias in making awards.

Our paper addresses these empirical and conceptual deficits. We seek to advance research on sub-group differences and variation in monetary payments with an analysis of 291 decisions for sexual offences by Victim Assist Queensland (VAQ). We ask whether outcomes differ by applicants' sex/gender ${ }^{2}$ and by societal constructs of ideal, real rape, and

\footnotetext{
${ }^{1}$ The term compensation is widely used in legislation and research to refer to money awarded in state schemes for crime victims, although it more properly refers to money awarded to a plaintiff in a civil court case. Thus, we use other terms throughout the paper such as monetary payments or awards.

${ }^{2}$ We use the term sex/gender to denote a socially produced embodiment. Sex is accurate when comparing males and females, but award outcomes are based on the incorporation of biological (sex) and socio-cultural (gender).
} 
credible victims. Our aims are three-fold: to describe the range of applicants and sexual victimisation they experienced, to compare amounts awarded, and to determine whether variation and bias are evident. Our analysis reveals differences in payments for the more serious category of sexual offences: male child victims were more likely to receive the maximum recognition payment than female child victims. Elements of real rape and credible victims were associated with payments to females 12 years and older: a positive bias was evident toward victims of stranger rape and toward sexual assault victims who reported to authorities right away.

State Payments to Violent Crime Victims: Emergence, Similarity, and Variation New Zealand was the first country to establish a state monetary scheme (1963), followed by Great Britain (1964), the United States (US) (California in 1965), and jurisdictions in Australia and Canada (1967) (Lamborn 1973; Newmark et al. 2003). Australian legislation was first enacted in New South Wales (NSW, 1967) and Queensland (1968). By 1983 all Australian jurisdictions had schemes. A compilation by the US Office for Victims of Crime (2005) lists 35 countries with schemes; the federated countries (Australia, Canada, and the US) alone have 70. Depending on the jurisdiction, decision-making sites are courts, tribunals, boards, legal units in government, and specialist administrative units. We use the term decision-makers to refer generally to those empowered to make awards, and assessors with reference to Queensland practices.

Compared to schemes in Britain and New Zealand, ${ }^{3}$ which operate as separate, quasiadministrative tribunals, those in Queensland and NSW were initially based on provisions in the criminal code. In Queensland, these permitted courts to order convicted defendants to pay money to victims, and at times, victims could apply to the state for an ex gratia payment.

\footnotetext{
${ }^{3}$ The Accident Compensation Commission established in 1974.
} 
With passage of the Criminal Offence Victims Act (COVA) in Queensland in 1995, upon court conviction or other eligibility criteria, a victim could make application to the court or to the state. A significant shift occurred in 2009 with passage of the Victims of Crime Assistance Act (VOCAA), which created a purely administrative scheme. Under VOCAA, victims apply to a government agency, Victim Assist Queensland (VAQ), and their application is assessed by a suitably qualified person, who is guided by legislation.

Monetary schemes today vary along three dimensions: what falls within the scope of a criminal injury, who is eligible, and what a payment is for (Miers 2014a: 113-23). Eligibility is restricted to victims of violent crime. Most schemes provide funds not only to primary (or direct) victims, but also to secondary victims (witnesses of the crime or parents/guardians of child victims) and related victims (family members of those who died). Eligibility is limited to those who did not conspire to commit the offence, cooperated with the police, and can provide evidence of the incident and injury (typically with a report to the police). Criminal conviction of an offender is typically not required today, as it once was. All schemes assume that they are a payer of last resort; thus, payments victims may have received from other sources are deducted from the final award.

There are three types of schemes. The first is criminal injuries compensation (CIC), what Miers (2014a: 119) terms the 'civil remedy surrogate'. It recompenses injury (noneconomic loss such as bodily injury, pain and suffering, loss of enjoyment of life) and actual and future expenses (economic loss, including medical and dental costs, loss of earnings) resulting from a violent crime. CIC schemes differ and have changed over time. For noneconomic loss (the larger component of a CIC scheme), British decision-makers are today guided by a set of detailed tariffs, structured by offence seriousness and injury. Previously, a table of maims was used. In the NSW 1987 Act, decision-makers had an open discretion (up to a maximum), which shifted in the 1996 Act to a detailed schedule of injuries. Under 
COVA 1995 in Queensland, decision-makers drew from a compensation table, which was amended in 1997 to include the adverse impact of sexual offences.

The second type is financial assistance (FA), which in Australia pays for expenses and awards a capped lump sum that is keyed to crime seriousness (a reduced non-economic loss component). The third type of scheme pays for expenses only. Schemes in Britain and New Zealand use CIC; and US jurisdictions, expenses only. Canadian jurisdictions use CIC and expenses only; and Australian jurisdictions, CIC and FA. Of the three types, CIC schemes give decision-makers the most latitude in awarding sums for non-economic loss; thus, there is likely to be considerable variation in CIC outcomes. FA schemes offer some discretion, but the lump sum is more tightly bound. Expenses only schemes give decision-makers the least discretion. Amounts awarded are generally highest in CIC jurisdictions and lowest for expenses only. FA jurisdictions are mid-way.

Four jurisdictions in Australia continue to use CIC, and four have shifted to FA. ${ }^{4}$ All Australian jurisdictions cover eligible crime-related expenses such as medical and dental costs, counselling, and loss of earnings. The capped lump sum in FA schemes is called a recognition or special assistance payment. For primary victims, the maximum is AU\$10,000 (except the ACT with a $\$ 26,500$ cap). The total payment (including expenses) that a primary victim may receive across Australia ranges from AU\$30,000 (Tasmania, for a single offence) to $\$ 100,000$ (South Australia) (see Victorian Law Reform Commission 2017, Appendix B, for a comparison of schemes in Australian states and territories).

\footnotetext{
${ }^{4}$ The CIC jurisdictions are the Northern Territory, South Australia, Tasmania, and Western Australia. For those shifting to FA, Victoria was the first (1996), then Queensland (2009), New South Wales (2013), and the Australian Capital Territory (ACT) (2016).
} 


\section{Variation in Awards}

Scant research exists on what victims actually receive. Government annual reports may provide aggregate averages, but they are not analytical. The most detailed English language analysis comes from the US (Newmark et al. 2003) and NSW (Salmelainen 1993, who analysed outcomes for a CIC scheme under the 1987 Act). The US study analysed variation in expenses awarded by state and by type of offence. State variation was substantial. In FY 2001, the average expense payment ranged from US $\$ 475$ in Nevada to $\$ 7,225$ in Illinois (Newmark et al. 2003: 11-16). A survey of adult claimants showed the average expense payment for sexual assault was \$US1,361 (Newmark et al. 2003: 101)..$^{5}$ The NSW study analysed applicant demographics (age, sex/gender, occupation), violent offence types and locations, types of injuries, and average awards by offence. During the study period, ${ }^{6}$ sexual assault of an adult received the highest average award (AU\$21,298) followed by sexual assault of a child (AU\$15,618) (Salmelainen 1993: vi).

Swanston et al. (2001) is the sole study to have examined factors associated with awards. Decisions under the NSW 1987 Act were analysed for 32 child sexual abuse cases. A median of AU $\$ 12,000$ was awarded for pain and suffering; amounts ranged from $\$ 750$ to $\$ 40,000$. There were no sex/gender differences in awards to child victims (Swanston et al. 2001: 46, 50). ${ }^{7}$ The authors concluded that 'none of the factors we considered might have been predictors of outcome were significant' and that 'magistrates do not operate at all

\footnotetext{
${ }^{5}$ Jurisdictions vary in how sexual offences are defined: some use sexual assault to include all types of sexual victimisation, and others distinguish rape and sexual assault. We use the term the author uses in reporting outcomes, or alternatively, the more generic term sexual offences.

${ }^{6}$ Under the NSW 1987 Act, the scheme maximum for pain and suffering was \$AU40,000, with an additional amount of up to $\$ 10,000$ for counselling or other expenses.

${ }^{7}$ Although the timeframes for both studies were similar (late 1980s to mid-1990s), Salmelainen's average is a mean and includes expenses, and Swanston et al.'s is a median and excludes expenses.
} 
consistently in the award of statutory compensation when given open-ended discretion'. Instead, there 'appeared to be a certain randomness in the amounts of money awarded' (Swanston et al. 2001: 56, 57). Newburn (1989: 14, 30) reached a similar conclusion after reviewing nearly 400 applications to the British Criminal Injuries Compensation Board. Having observed variation in outcomes 'from Board member to Board member and from victim to victim', he proposed that 'future enquiries should attempt to discern variations and patterns in the awards'. To date, few have taken up the challenge.

\section{Conceptualising Discretion and Bias}

Awards for non-economic loss to primary victims of crime, the focus of this paper, are based on decision-maker judgments of crime seriousness and on the physical and mental impact of crime on victims. Variation may arise from two sources, which may co-occur. One is individual decision-maker differences, like that observed by Swanston et al. (2001) and Newburn (1989), in which monetary outcomes vary by decision-maker. The second is a more patterned or consistent societal bias (both positive or negative) toward certain victims and contexts of victimisation. Our focus is on the latter, and to explain when and why bias may emerge, we draw from criminological concepts of deserving and ideal victims, socio-legal and criminological research on police and court responses to female victims of sexual offences, and psychological research on attributions of responsibility toward female and child victims of sexual offences.

\section{Deserving and ideal victims}

All state schemes are premised on social constructs of deserving, innocent, or blameless victims (Miers 1990, 2007, 2014a, 2014b). Beyond threshold eligibility criteria, such as a victim not having contributed to the injury suffered, how might these notions affect variation 
in awards? Christie's (1986: 19) concept of an ideal victim offers guidance in identifying the characteristics of victims who may attract greater sympathy (and a comparatively higher award) in the minds of decision-makers. Ideal victims are vulnerable or 'weak [that is], sick, old, or very young'. They are victimised in the course of 'carrying out a respectable project', and they cannot be blamed for what happened. Added to notions of vulnerability based on age or other victim characteristics is Carrabine et al.'s (2009: 159-61) 'hierarchy of victimisation', which differentiates ideal and non-ideal victims on the basis of social status. Those with low status or less power fall into the non-ideal category (examples they give are homeless and unemployed people). Thus, an analysis of the impact of discretion and bias on payments for sexual offences would consider victim-offender relations, the relative vulnerability and social status of victims and offenders, the type of sexual offence, and whether a victim had been drinking alcohol or engaged in reputedly less respectable activities before or during victimisation. Other violent crimes may be associated with different or additional factors.

\section{Female victims}

Constructs of real rape and credible victims, drawn from research on police and court responses to adult female victims of rape and sexual assault, add greater specificity. Introduced by Estrich (1987), the elements of real rape are stranger victimisation, in a public setting, evidence of serious physical injury, weapon use, and multiple assailants. Estrich (1987) and Krahé (2016), among others, argue that the more an offence conforms to this scenario, the more likely a victim will report it and the more likely it will progress in the criminal justice process. ${ }^{8}$ Related research has focused on elements associated with credible

\footnotetext{
${ }^{8}$ Real rape is infrequent compared to the more typical rape, which has a lone assailant whom the victim knows, no weapon, and few traces of serious physical injury.
} 
victims: having a reputedly good moral character (e.g., no history of drug or alcohol abuse or criminal offending); no risk-taking behaviour before the offence (e.g., walking alone at night, going home with a suspect); screaming and physically resisting an assault; and reporting it right away (Horney and Spohn 1996; LaFree 1989; Spears and Spohn 1996). A meta-analysis of experimental studies on attributions of responsibility toward adult female rape victims (Whatley 1996) found two recurring factors: victims with a 'questionable' character and those dressed 'provocatively' or in 'revealing clothes' were more often blamed for the assault. Other factors such as physical attractiveness and victim-offender (VO) relationship were less predictive.

\section{Child victims}

Based on prosecutors' charging decisions, Spears and Spohn (1996) argue that elements of a child's moral character and reputation, or of risk-taking, were not relevant to prosecutorial decisions to progress a child victim case. Instead, the salient factor was whether the child's case had a witness. Psychologists have carried out numerous experimental studies that vary the role of victim age, victim and offender sex/gender, and other factors that may influence attributions of responsibility toward child sexual offence victims. Scenarios of hypothetical cases are presented to research participants (typically undergraduate students). One settled finding is that older child victims of sexual offences (nearing or at puberty) are viewed by research participants as less credible and more blameworthy than younger victims - an outcome not noted at all in criminological research. A second is that male observers are 'more negative toward children of all ages/developmental stages' than female observers (Rogers et al. 2016: 2). ${ }^{9}$ Drawing on research published in the 1980s and early 1990s, Back

\footnotetext{
${ }^{9}$ This finding would be relevant for exploring variation among individual decision-makers.
} 
and Lips (1998: 1241) hypothesised that 'female [child] victims may receive more blame than male [child] victims because they best reflect the stereotype of the normal victim'. Their attribution study found sex/gender differences in the hypothesised direction, but the result was not statistically significant. Based on recent research, there is no settled finding on attributions of responsibility toward male and female child victims of sexual offences. The key differentiating factor appears to be the age of child victims (younger or older) and not sex/gender.

For victim age, Salmelainen's (1993) finding of a lower average award (including expenses) to child than adult victims of sexual assault may suggest that child victim cases were viewed as less serious or deserving than adult cases. However, the difference may also reflect the composition of sexual assaults ${ }^{10}$ and a greater ability of adult victims to claim expenses for loss of income.

Summarising the literatures, a complex set of factors shape judgments of crime seriousness and of deserving and blameless victims of sexual offences. Social status and inequalities (e.g., age and sex/gender) may matter, along with victimisation contexts and offence elements (victim-offender relations, victim resistance, frequency and duration of abuse). How, then, might these affect decisions in Queensland? We turn to the study's context, methods, and findings.

Study Context: Victim Assist Queensland

Under VOCAA, the Queensland FA scheme began on 1 December 2009. ${ }^{11}$ From December 2009 to September 2018, assessors for Victim Assist Queensland (VAQ) made

\footnotetext{
${ }^{10}$ Sexual assault would have included both penetrative and non-penetrative offences.

${ }^{11}$ FA is one of several VAQ programs and activities. Others provide information and referrals to victims; promote victim services; coordinate services, research, and training;
} 
determinations in 16,302 applications. Of these, $70 \%$ were for primary victims; $19 \%$, other victims; $1 \%$, funeral expenses; and $10 \%$ were deemed not eligible. ${ }^{12}$ Of the 11,468 eligible primary victims, assault had the largest share (53\%), followed by domestic violence (20\%) and sexual offences (19\%). The rest (robbery, burglary, and other offences) were $8 \%$. Of the 11,468 primary victims, the total average award by offence category ranged from AU $\$ 5,878$ (robbery) to 11,912 (sexual offences). ${ }^{13}$ From December 2009 to December 2018, VAQ received 375 applications for internal review. Of these, 37 applicants sought external review to the Queensland Civil and Administrative Tribunal (QCAT). Most VAQ decisions were upheld by QCAT, but QCAT increased the awards in three cases and returned four to VAQ for a reconsideration of new evidence. ${ }^{14}$

A Technical Report (Daly et al. 2019) describes the VAQ scheme in detail, which we sketch only briefly here for primary victims. A person must have been a victim of violence in Queensland and reported it to the police. This reporting requirement is waived for 'special primary victims' (including victims of sexual offences), when a report to a counsellor, psychologist, or doctor is accepted. For primary victims, the FA payment comprises eligible expenses and a recognition payment (RP). The latter, the focus of this paper, is based on four categories of seriousness: A, B, C, and D. Sexual offences are in the A and B categories. During the research period (decisions in 2012-13), category A was AU\$5,000 to \$10,000; and

engage in debt recovery; and administer funds to victim service providers.

${ }^{12}$ Legislated ineligibility criteria are various and include conspiring to commit the act of violence. The exclusions Smith and Galey (2018) discuss for sexual offences in Great Britain do not apply in Queensland.

${ }^{13}$ The total includes those who did and did not receive expenses, and the range excludes homicide and motor vehicle related offences.

${ }^{14}$ Internal review is carried out by another VAQ assessor at a higher level. Review outcomes were sourced by personal communication, Dean Corless, Director, VAQ, 11 January 2019. 
category $\mathrm{B}, \mathrm{AU} \$ 1,301$ to $\$ 3,500$. For primary victims, the objective is 'to give the victims amounts representing a symbolic expression by the State of the community's recognition of the injuries suffered by them' (VOCAA s 3(2)b, emphasis added). The payment can be spent entirely as a victim wishes. The maximum award for primary victims is $\$ 75,000$ plus $\$ 500$ for legal costs.

After an application is received and entered into the VAQ Case Management System (CMS), it is allocated to a VAQ assessor, who first determines the act of violence and RP category, ${ }^{15}$ and then decides expense amounts. After finalising their decisions, assessors generate a Statement of Reasons (SoR) that is sent to each applicant. The SoR outlines the rationale for the RP and expenses awarded. Of significance to this study, assessors had no guidelines for determining the amount of the RP for any offence, including sexual offences in categories $A$ or $B$.

When gathering data for the project, we had to identify an efficient and non-obtrusive way to understand the character and contexts of sexual victimisation, and to analyse how the assessors determined the RP. We did so by analysing the SoR, a formal document that makes frequent reference to legislation. When writing an SoR, an assessor draws upon a template with standard introductions and headings. Assessors add text in their own words, and this creates variability in the SoRs. One factor influencing SoR content was a shift in VAQ office practices, beginning in 2013, to reducing offence detail in an SoR, out of concern that it may

\footnotetext{
${ }^{15}$ Assessors can determine the category of violence in the absence of a person being charged or convicted, and they can override the legal classification of a charged or convicted offence. We (and VAQ staff) call this discretion reclassification, and movement always goes upwards; thus, for sexual offences, from category B to A. Of 291 cases, $16 \%$ were reclassified. Assessors also have discretion to uplift an offence to higher category of violence, based on a legislated list of aggravated harms. None of the 291 FAVE cases were uplifted.
} 
re-traumatise victims. ${ }^{16}$ This shift affected our ability to create a consistent picture of each case (see below, Coding the SoRs).

\section{Financial Assistance and Victims' Experiences (FAVE) Project}

\section{Methods}

The FAVE Project has three studies, all of which focus on primary victims of sexual offences. Study 1 analyses the FAVE dataset of recipients, outcomes, and assessors' reasons for decisions, the subject of this article. Reported elsewhere is Study 2, an online survey of those receiving FA, and Study 3, interviews with recipients (N=20) (Author/s 2018).

For Study 1, meetings were held in August and October 2013 between the senior author and VAQ staff to clarify the data that could be requested. It was decided that the sampling window would be 18 months: applications received and finalised from 1 July 2012 to 31 December $2013 .{ }^{17}$ Data were sought for primary victims of sexual offences of all ages, including partner violence with a sexual assault element. VAQ agreed to supply their CMS data (de-identified) on the cases and grants awarded, and the SoRs (de-identified) associated with each case. From 2014 to 2016, we cleaned and coded the CMS data, and read and coded the SoRs. In preliminary analyses of the merged CMS-SoR (FAVE) dataset, we discovered many errors and inconsistencies, including key dates (birth date and application date) and victim-offender relationships. This led to revising some variables and creating new ones. The initial CMS dataset had variables for sex/gender, Indigenous status (Aboriginal or Torres Strait Islander or not), age at time of offence, and state region of the application, together

\footnotetext{
${ }^{16}$ Personal communication, Dean Corless, (then) Acting Director, VAQ, 31 October 2016.

${ }^{17}$ Finalised means that a decision was made by a VAQ assessor to grant funds for general assessment; however, some FAVE cases had amendments that were incorporated in the outcomes. Victims can seek amendments for up to 6 years from the date assistance is granted; or if they were under 18 when it was granted, before turning 24 .
} 
with amounts awarded for the RP and each category of expenses. Each SoR was, on average, five pages (range 3 to 13 pages); there were a total of 1,651 text pages to code. Most were general assessments (1,400 pages), but some were interim and amendment assessments.

\section{Coding the SoRs}

The SoRs were coded with three aims. First, we wanted to know the character, context, and seriousness of each sexual offence: what occurred, the duration, and who was involved. When creating five seriousness variables, we drew from VOCAA's (s 81(2)) description of special primary victims. These were not only victims of sexual offences, but also child victims and those with impaired capacity, and those for whom offences were committed by a person in a position of power, influence, or trust. For these victims and offence contexts, victims can report an offence to a counsellor, psychologist, or doctor instead of a police officer. Another term in VOCAA is a series of related crimes (s 25(4) (a)), which refers to multiple incidents against a victim around the same time or over a period of time. These terms and phrases were used in the SoRs, and we coded them as indicators of offence seriousness, but legislation does not specify them as such. A fifth seriousness item was assessor mention of an age disparity (3 years or more) between victim and offender.

Second, we wanted to know what a victim did after the offence, specifically, when it was reported. This date, which was given in the SoRs, could then be linked to the CMS data on the date of the offence and application to VAQ. Third, we wished to test the impact of variable associated with real rape and credible victims on assessors' decisions. The five items for real rape were stranger relations, occurred in a public setting, evidence of physical violence or force, weapon used, and multiple assailants. For victim credibility, we identified positive and negative items. The four positive ones were victim reported to authorities within 3 days, reported within 7 days, mention of victim resistance, and the case had a court 
conviction. ${ }^{18}$ The three negative ones were mention of the victim having been at a bar or party before the offence, having used alcohol or drugs, or having accepted company from the alleged perpetrator.

Of the 17 items, we had complete information for four (victim-offender relations, reported within 3 days, reported within 7 days, ${ }^{19}$ case had a court conviction). For 13 items, we coded as 'yes' when an item was mentioned by an assessor in an SoR. Here we faced known limitations of content analyses of documents (Bowen 2009), especially when coding for the mention (or not) of theoretically informed pre-set variables. The SoR texts varied in the level of detail assessors gave for offence contexts and victims' behaviour, ${ }^{20}$ i.e., this was inconsistent across the SoRs. We could assume that mention of an item reflected an assessor's belief in its relevance to their award, or what justified it. However, when an item was not mentioned, it could mean that it was not relevant, or alternatively, that it was relevant, but the assessor chose not to mention it. To strengthen the analysis, we created four additional aggregate variables for 'any mention' of an item associated with real rape, positive credibility, negative credibility, and offence seriousness.

One aim in coding the SoRs - to know the context and seriousness of sexual offences - was partly realised: we had complete information for some items, but inconsistent information for others. The second aim was realised: we had complete data on when the offence occurred, when it was reported to authorities (except for 10 cases), its duration (if it

${ }^{18} \mathrm{~A}$ criminal conviction is not required under VOCAA, but it was under previous legislation. Of 291 cases, 38\% had criminal convictions under previous legislation, and $10 \%$ under VOCAA. We reasoned that cases with convictions may have had more credibility than those reported to authorities alone.

${ }^{19}$ Except for 10 cases when the date of report was not given in the SoR.

${ }^{20}$ During the research period, the VAQ office had 10 assessors; we did not have information on who the assessors were, nor seek to analyse award variation by assessor. 
occurred over a period of time), and when VAQ received the application —all of which could be linked to a victim's age. The third aim — to test the impact of real rape and credible victims variables - was realised by identifying what an assessor mentioned in the SoR (i.e., an item's relevance or justification). However, we cannot be sure what the absence of a mention means (or 'any mention' for the aggregate variables). Despite this, the SoRs reveal what assessors chose to communicate to victims, and using Bowen's (2009) evaluation criteria, the quality of the evidence is sufficient, we believe, to warrant confidence in the findings.

\section{Findings}

Applicants and sexual victimisation experienced

Our analysis comprises all primary victims of sexual offences whose applications were received and finalised by VAQ from 1 July 2012 to 31 December 2013. Of 291 cases, 65\% were victims of category A offences: rape (40\%) and maintaining a sexual relationship with a child $[\mathrm{MSR}](25 \%)$. The rest were victims of category B offences: sexual assault (12\%) and indecent treatment of a child under 16 [ITC] (23\%). Rape (category A) includes varied types of penetrative sex; and sexual assault (category B), varied types of non-penetrative sexual assault. MSR (category A) is defined as an adult who maintains 'an unlawful sexual relationship with a child that involves unlawful sexual acts'; and ITC (category B), 'any person' who 'indecently deals with a child' or exposes a child to indecent acts (Queensland Criminal Code, Chapter 32). ${ }^{21}$ In the FAVE sample all MSR and ITC victims were under 16 years of age.

\footnotetext{
${ }^{21}$ The maximum penalty for rape and MSR is life imprisonment; for sexual assault and ITC, 14 years' imprisonment, but subject to further enhancements, depending on the age of the victim.
} 
Most victims were female (87\%) and non-Indigenous (87\%, when known). ${ }^{22}$ For the $68 \%$ of cases for which an alleged or convicted perpetrator could be determined, all were male. Victim-offender (VO) relations were family members or relatives (47\%), those known or well-known to the victim (44\%), and strangers (9\%).

Age and on-going victimisation. Research on US schemes shows that sexual assault victims were the youngest (average age 18) compared to other applicants (Newmark et al. 2003: 101). However, we had not expected such a young profile of victims in the FAVE sample: a large share $(46 \%)$ was under 12 , and $78 \%$ were under 18 when the incident occurred or the victimisation began. Age is related to a second unexpected finding: nearly half of the 291 victims (48\%) had been victimised over a period of time ('on-going victimisation'), ranging from 1 week to over 5 years. The median and mean duration were 1.5 and 2.5 years, respectively. ${ }^{23}$

There was nothing in the literature (government reports, official police data, victimisation surveys, victim interviews) to have prepared us for such a large share of child victims, 59\% of whom had experienced on-going victimisation. In part, this is because surveys do not include young victims, and in part, government annual reports give sparse information on victim demographics by type of violent offence. Moreover, for ethical reasons, interview studies are often restricted to victims aged 18 and over. The age of sexual offence victims in the FAVE sample may be specific to Queensland, but we cannot know until research in other jurisdictions is carried out.

\footnotetext{
${ }^{22}$ Of 291 cases, Indigenous status (Aboriginal or Torres Strait Islander or not) was known in $261(90 \%)$. Outcomes by Indigenous status will be reported in another article.

${ }^{23}$ For cases with on-going victimisation, we calculated age from the start of the victimisation. In contrast, VAQ calculated age by using the end date in all cases, including those with ongoing victimisation. Had we used VAQ's method, $34 \%$ of victims were under 12 , and $76 \%$ were under 18. Rape cases with on-going victimisation may include rape and other offences such as ITC or assault, but the RP is based on the most serious offence.
} 
Other case elements. Of 291 cases, $98 \%$ were reported to the police (the rest were reported to a counsellor). A large share (48\%) had a court conviction. Cases varied in the length of time from victimisation to application to VAQ. ${ }^{24}$ For most (59\%), the time was 3 years or less, but for $16 \%$, it was greater than 10 years (range $>10$ to 44 years). This long time span may seem surprising, but it can be explained. The older cases were eligible under repealed legislation and were assessed under transitional arrangements in VOCAA, after having been subject to often lengthy court processes.

Sex/gender. Many variables had significant sex/gender differences. The most striking were age at the time of the incident or start of sexual victimisation, and whether it was a single incident or on-going. For 291 cases, all the males were under 18 compared to $75 \%$ of females. The mean age for males was just over 10 years (10.2), and for females, 16.5. The age range for males was 3 to 17 ; but for females, it was under a year to 65.4 years. A higher share of males $(68 \%)$ than females $(45 \%)$ had experienced on-going victimisation. There were also differences for VO relations: a higher share of males was victimised by those wellknown or known to them (57\%) compared to females, who were more likely to be victimised by immediate family members or relatives (49\%).

\section{Money awarded: overview}

For 291 cases, the average RP was $\$ 7,257,71 \%$ received the maximum RP, and 69\% received expenses (Table 1). A higher share of category A cases received the maximum RP (80\% for rape and MSR) compared to those in category B (53\% and 56\% for sexual assault and ITC). We asked VAQ assessors why this occurred. They told us that when comparing rape in category A and sexual assault in B, rape was 'the worst of the worst' and therefore

\footnotetext{
${ }^{24}$ For this analysis, time was determined from the date of the incident or the end date of victimisation (if on-going) to the date VAQ received the application.
} 
harder to grade whereas for sexual assault, there were many more types of offending to consider (such as touching over or under clothing and how often). In general, category A offences were 'clearly serious' in their minds, whereas category B was 'not as serious', which led to their giving these cases a higher degree of scrutiny.

[Table 1 about here]

\section{Money awarded: sex/gender differences and child victims}

Table 2 shows the average RP for category A and B offences. For category A all the males received the maximum $\mathrm{RP}$, but $78 \%$ of females did. The average payment for males $(\$ 10,000)$ was higher than that for females $(\$ 9,396)$. For category $B$, similar proportions received the maximum $\mathrm{RP}(53 \%$ and $56 \%$ for males and females, respectively), and the average RP was similar for both $(\$ 3,021$ and $\$ 3,073$, respectively).

With no variance in the male RP, t-tests of average (mean) sex/gender differences could only be indicative because such tests assume a normal distribution; moreover, tests for percentage differences (using Fisher's Exact Test) would ideally have had a larger number of male cases. In the right-hand column, sex/gender differences are noted when a $90 \%$ confidence interval around the mean did not include zero and Fisher's Exact Test was significant at $\mathrm{p}<.10$.

[Table 2 about here]

Our empirical attention now shifts to category A. Why did all the males receive the maximum RP, and why was their average payment higher? To address this, we analysed rape and MSR cases separately because each had distinctive sex/gender differences.

Rape. For rape, all the males were under 18 , but $62 \%$ of females were (Table $3 a$, full sample). The age range at victimisation was more compressed for males (3.0 to 16.9 years) than females (1.6 years to 65.4 years); thus, the average age at victimisation was younger for males (8.8) than females (18.5). A higher share of males (67\%) than females (30\%) 
experienced on-going victimisation, but the duration was longer for females. There were small differences in VO relations and the percent of cases with court convictions.

[Table 3 about here]

The average RP for males was $\$ 10,000$, and for females, $\$ 9,381$. One potential explanation was that males more often experienced on-going victimisation and were younger when victimised. Assessors may have placed greater symbolic value on on-going (not single incident) victimisation, which was more frequent in child than adult cases. Both would have benefitted monetary awards to males. We could not carry out a multivariate analysis to test this explanation; instead we chose the method of exact matching of male and female pairs. ${ }^{25}$ First, we removed females aged 18 and over, and then, separately listed the male and female cases by on-going or single incident victimisation. Matched pairs were then identified by VO relations, ${ }^{26}$ and then by age of victimisation and duration of victimisation (if on-going). We produced three samples of matched pairs (using a differing order of selection variables), examined the distributions of the key variables, and selected the sample most closely matched. Table $3 \mathrm{~b}$ (matched pairs) shows the results.

The male and female distributions for the matched pairs were nearly identical in age and age range of victimisation, percentage on-going victimisation, and duration of victimisation and its range. A somewhat higher share of male cases had court convictions, and a somewhat higher share of females was victimised by immediate family and relatives, but both had the same share of stranger victimisation. For the RP, seven of nine females received the maximum $\mathrm{RP}$, and the average was $\$ 9,500$. When moving from the full sample

\footnotetext{
${ }^{25}$ After the protocol for identifying matched pairs was decided, it was carried out independently by two researchers. The results were then compared and moderated.

${ }^{26}$ The three VO categories were family and relatives, known or well-known, and strangers.
} 
to the matched pairs, the gap in the average award reduced from $\$ 619$ to $\$ 500$, with the male average remaining somewhat higher.

MSR. MSR cases are more easily compared because all the victims were under 16, and by definition, victimisation was on-going. As shown in Table 4a (full sample), females were younger (9.6 years) than males (12.0) and the duration of their victimisation was somewhat longer (10 months). The strongest difference was VO relations: for $78 \%$ of females, perpetrators were immediate family and relatives (typically stepfathers and fathers); and for $78 \%$ of males, they were well-known or known (family friends, a neighbour, a professional). Whereas all males received the maximum RP of $\$ 10,000,77 \%$ of females did, with an average of $\$ 9,422$.

The MSR cases were matched by selecting pairs by VO relations, ${ }^{27}$ and then victim age and duration of victimisation. Table $4 \mathrm{~b}$ (matched pairs) shows the results. The male and female distributions for the matched pairs were identical or nearly identical for age (and age range), duration of victimisation (and duration range), VO relations, and percentage of cases with court convictions. Despite this, five of nine females received the maximum RP, with an average of $\$ 9,167$. Upon closer inspection, this occurred because female child victims were awarded lower sums when perpetrators were family friends or other family members (defined by VAQ as non-biologically related kin). By contrast, males received the maximum RP, no matter what the VO relationship. When moving from the MSR full sample to the matched pairs, the male/female gap in the average RP increased from $\$ 578$ to $\$ 833$. Positive assessor bias toward male child victims was evident in the MSR cases, even more so than for rape cases.

[Table 4 about here]

\footnotetext{
${ }^{27}$ In most cases, we were able to select pairs by detailed VO relations such as father, stepfather, and friend of the family, but otherwise, we used the three VO categories.
} 
Category A. We combined the rape and MSR matched pairs to analyse the outcomes for all 18 category A cases. The average RP for males and females was $\$ 10,000$ and $\$ 9,333$ (6.7\% lower for females). The percent receiving the maximum RP was 100\% (male) and 67\% (female), a gap of 33 percentage points. The number of matched pairs is low (18), and other unmeasured variables may explain award variation. However, the evidence shows sex/gender differences, with a positive assessor bias toward male child victims in category A offences.

\section{Female victims: real rape and credible victims}

We analysed females aged 12 and older, with separate analyses of rape $(\mathrm{N}=75)$ and sexual assault $(\mathrm{N}=29)$. A series of $2 \times 2$ tables tested whether elements associated with real rape, credible victims, and seriousness were related to assessors awarding the maximum RP. We used one-tailed tests of statistical significance because we had hypothesised the direction of effects, and used a relaxed error level of $\mathrm{p}<.10$ and $<.20$. We hypothesised that some seriousness elements should be related to victims receiving the maximum RP, but those associated with real rape and credible victims should not, at least not ideally.

Of six items for rape, three were associated with a higher likelihood of victims receiving the maximum RP: stranger relations, evidence of physical violence or force, and any real rape element. To illustrate, $92 \%$ of the stranger cases received the maximum, but $73 \%$ of the non-stranger cases did; $89 \%$ of cases having any real rape element received the maximum, but $65 \%$ of those without any element did. For rape, no positive credibility item was related to receiving the maximum RP (timely reporting of the offence, mention of victim resistance, case had a court conviction). Although $63 \%$ were reported within 3 days and $72 \%$ within 7 days, neither was related to receiving the maximum RP. A high share of rape cases $(85 \%)$ had any positive credibility item, but it was not related to receiving the maximum. The 
negative credibility items had a relatively stronger impact, although they were noted less often by assessors. Mention that the victim had been using alcohol or drugs, accepted company from the offender, or mention of any negative credibility item was inversely related to a victim's receiving the maximum RP. One seriousness item affected the likelihood of receiving the maximum: when the offence was part of a series of crimes (on the day or over time).

For sexual assault, no real rape element had the expected relationship to the maximum $\mathrm{RP} .{ }^{28}$ The variables that did were timely reporting of the offence to authorities (within 3 days or within 7 days), mention that a victim was young, and mention of any seriousness item.

Update: Change in July 2017

As of 1 July 2017, when amendments to VOCAA took effect, assessor discretion no longer exists when awarding the RP, once the category of violence is determined. ${ }^{29}$ All category A cases now receive $\$ 10,000$, and all category B cases, $\$ 3,500$. This change was one of 15 recommendations to amend VOCAA, proposed by the Department of Justice and Attorney General (DJAG) in December 2015. The review consultation process began in late 2013, when DJAG sought submissions from government and non-government service providers, as well as VAQ staff. In its final report, DJAG (2015: 17) said there was 'no specific formulation for making decisions about what a victim should be paid within the broad range', which '[led] to inconsistency in decisions'. It reasoned that flat payments would make 'decisions ... more streamlined and consistent across applications'. The proposed change to the RP occurred before we had discovered award variation by victim sub-groups. Thus, the

\footnotetext{
${ }^{28}$ Mention was made in two cases that the sexual assault occurred in a public setting, but neither received the maximum RP.

${ }^{29}$ Assessors still have discretion to determine the category of offence and to uplift it to a higher category.
} 
findings from the FAVE Project did not prompt the government's change to the RP, but we can say now that it was the right decision.

\section{Discussion and Implications}

Research on state payments to victims of violent crime has focused on scheme parameters, their variation and change in legislation over time, and victims' experiences and judgments of them. Ours is the first study to probe more deeply into the amounts actually awarded to victims, variation by victim sub-group, and potential bias in decisions. We profiled victims and their experiences of sexual victimisation in greater depth than previous research. Despite these contributions, the study has three limitations.

First, it was of sexual offences only, not a broader range of violent offences; and it was of primary victims, not related or secondary victims. At the outset, we decided it was better to understand one type of offence in depth, rather than describing outcomes for a larger set of offences, but more superficially. In Queensland, the focus on primary victims of sexual offences permitted an analysis of RPs for the most serious category A cases. Had we analysed assault or robbery, we would have been limited to a more compressed range of RPs in categories B and C. In looking to future research on victim sub-groups and the impact of decision-maker discretion, we recommend a focus on one type of offence in depth. This is because societal constructs of ideal, deserving, or credible victims will vary by the type of offence, as will elements of offence seriousness and related harm.

Second, the analysis of sex/gender differences in category A awards was hampered by a low number of male cases, too few to carry out multivariate analyses. It was also affected by differing male and female distributions for the independent variables (age of victimisation, on-going or single incident, VO relations) and no variance in the average RP for males. We addressed this problem in a systematic way by creating 18 matched pairs, selecting a female 
case that was the same or nearly the same as the male case for several key variables. Then, we compared the outcomes.

Third, for the impact of elements associated with real rape and credible victims, most items were coded as 'yes' when assessors mentioned them in the SoRs. The lack of a mention could mean it was not relevant to a decision; or alternatively that it was relevant, but the assessor chose not to mention it. As Bowen (2009: 31-32) points out, 'insufficient detail' (in our study, inconsistent detail) is a common limitation when coding documents. To address it, he recommends that researchers evaluate the evidence: its relevance to the research problem, its quality, and its original purpose. In doing so, we have confidence that the evidence was sufficient to test the impact of real rape and credible victims.

Our study analysed decisions in sexual offence cases over an 18-month period (July 2012 to December 2013). Two unexpected findings were the young age of victims (78\% under 18) and a high share who experienced victimisation over a period of time (48\%). There was nothing in the research literature to have anticipated this profile of cases. Indeed, analysts often assume that sexual offence applicants are adults, not children or youth (e.g., Galey and Smith 2018). There were sex/gender differences in the RP for the more serious category A cases (rape and MSR), but not category B (sexual assault and ITC). For rape, assessors appeared to be positively biased toward on-going victimisation, which was more frequent in child than adult cases. This seemed a likely explanation for the higher RP for male than female rape cases. However, in the rape matched pairs, the male/female gap in the average RP was reduced, but differences remained.

For MSR, all victims were under 16 and had experienced on-going victimisation. When moving from the MSR full sample to the matched pairs, the male/female gap in the average RP and percentage receiving the maximum RP did not narrow, but grew wider. No matter what the VO relationship was, male child victims of MSR received the maximum RP; 
by comparison, female child victims' awards were lower when perpetrators were known or well-known, but not family members. In the matched pairs for category A, the average RP for males and females was, respectively, $\$ 10,000$ and $\$ 9,333$, and the gap in receiving the maximum RP was 33 percentage points.

What, then, explains a positive bias toward male child victims in category A cases? Specifically, why, no matter what the variable - VO relations, single incident or on-going victimisation, duration (if on-going), or younger age — did male child victims receive the maximum RP? 'Being male' (or a male child) appears to have been an overriding victim status for which other case information was less relevant to assessors. Perhaps also, as Back and Lips (1998: 1241) suggest, male child victims did not reflect 'the stereotype of the normal victim' of child sexual offences, as females did. Their insight can be deepened, when we consider the profile of perpetrators in the FAVE sample. When it could be determined, all were male; and detailed VO relations for the 18 matched pairs show that all were adults. Sexual victimisation of a male child by an adult male may have been viewed by assessors as unambiguously wrong, compared to that of a female child. Put another way, an adult male sexually abusing a male child cannot be readily interpreted as 'sex' or caused by child seduction, as is possible for a female child victim. With scant research on sex/gender differences in awards, future research should explore such differences for both child and adult victims. In light of the attribution of responsibility literature, the sex/gender of decisionmakers may also be relevant. However, we found no variation in awards between younger and older child victims, as anticipated from this literature. ${ }^{30}$

Bias, both positive and negative toward females aged 12 and older, was evident in the analysis of elements associated with real rape and credible victims. There was positive bias

\footnotetext{
${ }^{30}$ For category A, all male child victims received the maximum RP no matter what their age. For all female child victims in category A, there were no differences in the percentage receiving the maximum RP for younger (under 12$)$ and older $(12$ to $<18)$ victims.
} 
toward stranger rape, elements associated with stranger rape, and timely reporting of sexual assault (within 3 or 7 days). As expected from the literature on ideal and credible victims, there was negative bias toward rape victims when mention was made of having alcohol or drugs and accepting company from an offender.

Two implications flow from our research. First, there are parallels between the exercise of discretion in state schemes for crime victims and in criminal justice decisionmaking. The cross-over between real rape and credible victims, concepts drawn from criminal justice, is one example. The impact of social inequalities, and of positive and negatives biases toward certain groups and offending/victimisation contexts, should be investigated for decision-making in state schemes for victims, just as it has for decades in criminal justice responses to those accused of crime. Ours is the first study to analyse victim sub-group differences in detail and to identify factors associated with awards. It is also the first to elaborate upon and test the impact of ideal, real, and credible victims on award variation and bias in awards. We call upon researchers and governments (who hold the data) to pursue and expand this new area of research.

Second, in Australia, all FA jurisdictions should follow Queensland's lead and remove decision-maker discretion when determining the recognition payment, once the category is decided. NSW has already done so, and Victoria and the ACT should consider it. For CIC schemes in Australia, Canada, Great Britain, New Zealand, and elsewhere, we would expect to see even greater variation and bias in awards for non-economic loss, whether by administrative or judicial decision-makers, because there is greater latitude in amounts that can be awarded. We have no reason to think that CIC decision-makers would be affected any less by patterned societal biases (positive and negative) than the FA assessors in our study.

A considerable expenditure of state funds is awarded annually in payments to victims of violent crime, but few have investigated whether individual decision-maker or patterned 
bias exists in the amounts awarded. It is incumbent on all jurisdictions, and especially those using CIC and FA schemes, to more rigorously analyse their applicant files and decisions, with attention to who is applying, how decisions are reached, variation in awards, and why amounts may differ.

\section{Funding}

This work was supported by Australian Research Council Discovery Grants [grant numbers DP130103775 and DP170101470].

\section{Acknowledgments}

We thank Victim Assist Queensland staff for their support and assistance in carrying out the research, and especially Nicola Doumany (Director, December 2009 to October 2016) and Dean Corless (Acting Director and Director, October 2016 to present). We are indebted to Victoria Meyer for her cheerful and dedicated research assistance throughout the project.

\section{REFERENCES}

Ashworth, A. (1986), 'Punishment and Compensation: Victims, Offenders and the State', Oxford Journal of Legal Studies, 6/1: 86--22.

BACK, S. and LIPS, H. (1998), 'Child Sexual Abuse: Victim Age, Victim Gender, and Observer Gender as Factors Contributing to Attributions of Responsibility', Child Abuse \& Neglect, 22/12: 1239--52.

BARrett MeYering, I. (2010), 'Victim Compensation and Domestic Violence: A National Overview', Stakeholder Paper No. 8, Australian Domestic \& Family Violence Clearinghouse. University of New South Wales.

Bowen, G. (2009), 'Document Analysis as a Qualitative Research Method', Qualitative Research Journal, 9/2: 27--40.

Carrabine, E., Cox, P., Lee, M., Plummer, K. and South, N. (2009), Criminology: A Sociological Introduction, $2^{\text {nd }}$ edition. Routledge.

CASA House (1997), Just Tokens? A Report on the Experience of Victim/Survivors of Sexual Assault when Making Application for Crimes Compensation. CASA House. 
Christie, N. (1986), 'The Ideal Victim', in E. A. Fattah, ed., From Crime Policy to Victim Policy', 17--30. Palgrave Macmillan.

DAly, K., Holder, R. and MeYer, V. (2019). The FAVE Project, Financial Assistance and Victims' Experiences, Technical Report No. 6: Contexts, Data, and Decisions by Victim Assist Queensland for Sexual Offences. Brisbane: School of Criminology and Criminal Justice and Griffith Criminology Institute, Griffith University.

DAVIES, I. (1991), 'Compensation for Criminal Injuries in Australia: A Proposal for Change in Queensland', Bond Law Review, 3/1: 1--24.

DEPARTMENT OF Justice AND ATTORNEy GENERAL [DJAG] (2015), Final Report on the Review of the Victims of Crime Assistance Act 2009. Queensland Government.

DufF, P. (1998), 'The Measure of Criminal Injuries Compensation: Political Pragmatism or Dog's Dinner?,' Oxford Journal of Legal Studies, 18: 105--42.

EstRICH, S. (1987), Real Rape. Harvard University Press.

Freckelton, I. (2001), Criminal Injuries Compensation: Law, Practice and Policy. LBC Information Services.

Holder, R. AND DALY, K. (2018). 'Recognition, Reconnection, and Renewal: The Meaning of Money to Sexual Assault Survivors', International Review of Victimology, 24/1: $25--46$.

HoRney, J. and SpoHn, C. (1996), 'The Influence of Blame and Believability Factors on the Processing of Simple Versus Aggravated Rape Cases', Criminology, 34/2: 135--61.

KRAHÉ, B. (2016), 'Societal Responses to Sexual Violence Against Women: Rape Myths and the 'Real Rape' Stereotype', in H. Kury, S. Redo, and E. Shea, eds., Women and Children as Victims and Offenders: Background, Prevention, Reintegration, 2: 671-700. Springer Nature, Springer International Publishing.

LAFreE, G. (1989), Rape and Criminal Justice: The Social Construction of Rape. Wadsworth.

LAMBORN, L. L. (1973), 'The Propriety of Governmental Compensation of Victims of Crime', The George Washington Law Review, 41/3: 446--70.

MIERS, D. (1990), Compensation for Criminal Injuries. Butterworths.

MIERS, D. (2007), 'Looking Beyond Great Britain: The Development of Criminal Injuries Compensation', in S. Walklate, ed., Handbook of Victims and Victimology, 337--62. Willan Publishing.

MiERS, D. (2014a), 'State Compensation for Victims of Violent Crime,' in I. Vanfraechem, A. Pemberton, and F. Ndahinda, eds., Justice for Victims: Perspectives on Rights, Transition and Reconciliation, 105--39. Routledge. 
MiERS, D. (2014b), 'Offender and State Compensation for Victims of Violent Crime: Two Decades of Development and Change', International Review of Victimology, 20/1: $145--68$.

Mulder, J. (2013), Compensation. The Victim's Perspective. Wolf Publishing.

NEWBURn, T. (1989). The Settlement of Claims at the Criminal Injuries Compensation Board. Home Office Research Study No. 112. HMSO.

Newmark, L., Bonderman, J., Smith, B. and Liner, B. (2003), National Evaluation of State Victims of Crime Act Assistance and Compensation Programs: Trends and Strategies for the Future. Urban Institute, Justice Policy Center.

Office of JustiCe Programs (2015), Nationwide Analysis, 2014 Victims of Crime Act, Performance Report, State Compensation Program. US Department of Justice.

OFFICE FOR VICTIMS OF CRIME (2005), Directory of International Crime Victim Compensation Programs 2004-2005. US Department of Justice.

https://www.ncjrs.gov/ovc archives/reports/intdir2005/alphaindex.html\#a. Accessed 22 June 2016.

Rogers, P., Lowe, M. and Reddington, K. (2016), 'Investigating the Victim Pseudomaturity Effect: How a Victim's Chronological Age and Dress Style Influences Attributions in a Depicted Case of Child Sexual Assault', Journal of Child Sexual Abuse, 25/1: 1--19.

Salmelainen, P. (1993), Criminal Victim Compensation: A Profile of Claims, Claimants and Awards. NSW Bureau of Crime Statistics and Research.

SMITH, O. and Galey, J. (2018), 'Supporting Rape Survivors through the Criminal Injuries Compensation Scheme: An Exploration of English and Welsh Independent Sexual Violence Advisors' Experiences', Violence Against Women, 24/9: 1091--09.

Spears, J. and Spohn, C. (1996), 'The Genuine Victim and Prosecutors' Charging Decisions in Sexual Assault Cases', American Journal of Criminal Justice, 20/2: 183--205.

Swanston, H., Parkinson, P., Shrimpton, S., O’Toole, B. and OAtes, R. (2001), 'Statutory Compensation for Victims of Child Sexual Assault: Examining the Efficacy of a Discretionary System', International Review of Victimology, 8: 37--62.

THOMSON REUTERS FOUNDATION (2015), Comparative Report on National State Compensation Schemes. Thomson Reuters Foundation.

ViCTORIAN LAW REFORM COMMISSION (2017), Review of the Victims of Crime Assistance Act 1996, Supplementary Consultation Paper, August 2017. Victorian Law Reform Commission.

WhatLey, M. (1996), 'Victim Characteristics Influencing Attributions of Responsibility to Rape Victims: A Meta-Analysis', Aggression and Violent Behavior, 1/2: 81--95. 
Table 1. Financial assistance outcomes for sexual offences (2012-13)

\begin{tabular}{|c|c|c|c|c|c|}
\hline & & $\begin{array}{l}\text { average } \\
\operatorname{RP}(\$)\end{array}$ & $\begin{array}{c}\% \\
\text { received } \\
\text { maximum } \\
\text { RP }\end{array}$ & $\begin{array}{c}\% \\
\text { received } \\
\text { expenses }\end{array}$ & $\begin{array}{c}\text { average } \\
\text { total } \\
\text { payment* } \\
\text { (\$) }\end{array}$ \\
\hline \multirow[t]{2}{*}{ all cases $(\mathrm{N}=291)$} & & 7,257 & 71 & 69 & 9,815 \\
\hline & $\begin{array}{c}N=291 \\
(\%)\end{array}$ & & & & \\
\hline \multicolumn{6}{|c|}{$\begin{array}{l}\text { category A (range } \$ 5,000 \text { to } \\
10,000 \text { RP) }\end{array}$} \\
\hline rape $(\mathrm{N}=118)$ & 40 & 9,428 & 80 & 80 & 12,784 \\
\hline MSR (<16 yrs) ( $N=73)$ & 25 & 9,493 & 80 & 60 & 11,798 \\
\hline \multicolumn{6}{|c|}{$\begin{array}{l}\text { category B (range } \$ 1,301 \text { to } \\
3,500 \mathrm{RP} \text { ) }\end{array}$} \\
\hline sexual assault $(\mathrm{N}=34)$ & 12 & 3,057 & 53 & 62 & 5,052 \\
\hline ITC (<16 yrs) (N=66) & 23 & 3,067 & 56 & 65 & 4,766 \\
\hline
\end{tabular}

$\mathrm{RP}=$ recognition payment

*Total average payment includes those who did and did not receive an expense payment. 
Table 2. Category A and B. Recognition payment (RP) for male/female cases

\begin{tabular}{|c|c|c|c|}
\hline & $\begin{array}{c}\text { male } \\
(\mathrm{N}=18)\end{array}$ & $\begin{array}{r}\text { female } \\
(\mathrm{N}=173)\end{array}$ & comment on difference* \\
\hline \multicolumn{4}{|l|}{ category A } \\
\hline average RP (\$) & 10,000 & 9,396 & male higher \\
\hline \multirow[t]{2}{*}{$\%$ received maximum $\mathrm{RP}$} & 100 & 78 & male higher \\
\hline & $\begin{array}{c}\text { male } \\
(\mathrm{N}=19)\end{array}$ & $\begin{array}{l}\text { female } \\
(\mathrm{N}=81)\end{array}$ & \\
\hline \multicolumn{4}{|l|}{ category B } \\
\hline average RP (\$) & 3,021 & 3,073 & \\
\hline$\%$ received maximum $\mathrm{RP}$ & 53 & 56 & \\
\hline
\end{tabular}

*Difference noted when a $90 \%$ confidence interval around the mean does not contain zero, or Fisher's Exact Test is significant at $p<.10$. 
Table 3. RAPE: Recognition payment (RP) and key variables for the (a) full sample and (b) matched pairs

\begin{tabular}{|c|c|c|c|}
\hline (a) Rape: full sample & $\begin{array}{l}\text { male } \\
(\mathrm{N}=9)\end{array}$ & $\begin{array}{c}\text { female } \\
(\mathrm{N}=109)\end{array}$ & comment on difference* \\
\hline average RP (\$) & 10,000 & 9,381 & male higher \\
\hline$\%$ received maximum $\mathrm{RP}$ & 100 & 78 & \\
\hline age at incident or start of victimisation (yrs) & 8.8 & 18.5 & male younger \\
\hline range (yrs) & 3.0 to 16.9 & 1.6 to 65.4 & \\
\hline$\%$ under 18 & 100 & 62 & all males under 18 \\
\hline \% on-going & 67 & 30 & male higher \\
\hline duration on-going (yrs) & $(N=6) \quad 1.1$ & $(N=33) 2.5$ & female longer \\
\hline range (yrs) & 0.1 to 2.3 & 0.5 to 10.0 & \\
\hline VO relationship: family or relatives & 33 & 39 & \\
\hline well-known or known & 45 & 48 & \\
\hline stranger & 22 & 13 & \\
\hline$\%$ case had court conviction & 44 & 34 & \\
\hline (b) Rape: matched pairs & male $(\mathrm{N}=9)$ & female $(N=9)$ & \\
\hline average RP (\$) & 10,000 & 9,500 & \\
\hline$\%$ received maximum $\mathrm{RP}$ & 100 & 78 & \\
\hline age at incident or start of victimisation (yrs) & 8.8 & 9.0 & \\
\hline range (yrs) & 3.0 to 16.9 & 4.7 to 17.0 & \\
\hline$\%$ under 18 & 100 & 100 & \\
\hline \% on-going & 67 & 67 & \\
\hline duration on-going (yrs) & $(N=6) 1.1$ & $(N=6) 0.9$ & \\
\hline range (yrs) & 0.1 to 2.3 & 0.2 to 2.0 & \\
\hline VO relationship: family or relatives & 33 & 45 & \\
\hline well-known or known & 45 & 33 & \\
\hline stranger & 22 & 22 & \\
\hline$\%$ case had court conviction & 44 & 22 & \\
\hline
\end{tabular}

*Difference noted when a $90 \%$ confidence interval around the mean does not contain zero, or Fisher's Exact Test is significant at $p<.10$. 
Table 4. MSR: Recognition payment

(RP) and key variables for the

(a) full sample and (b) matched pairs

\begin{tabular}{|c|c|c|c|}
\hline (a) MSR: full sample & $\begin{array}{l}\text { male } \\
(\mathrm{N}=9)\end{array}$ & $\begin{array}{l}\text { female } \\
(\mathrm{N}=64)\end{array}$ & comment on difference* \\
\hline average RP (\$) & 10,000 & 9,422 & male higher \\
\hline$\%$ received maximum $\mathrm{RP}$ & 100 & 77 & \\
\hline age at start of victimisation (yrs) & 12.0 & 9.6 & female younger \\
\hline range (yrs) & 10.0 to 15.0 & $<1$ to 15.3 & \\
\hline$\%$ under 16 & 100 & 100 & \\
\hline$\%$ on-going & 100 & 100 & \\
\hline duration on-going (yrs) & 2.4 & 3.2 & \\
\hline range (yrs) & 0.7 to 4.3 & 0.3 to 9.1 & \\
\hline VO relationship: family or relatives (\%) & 22 & 78 & sharp differences \\
\hline well-known or known & 78 & 22 & \\
\hline$\%$ case had court conviction & 89 & 83 & \\
\hline (b) MSR: matched pairs & $\begin{array}{l}\text { male } \\
(\mathrm{N}=9)\end{array}$ & $\begin{array}{c}\text { female } \\
(\mathrm{N}=9)\end{array}$ & \\
\hline average $\mathrm{RP}(\$)$ & 10,000 & 9,167 & male higher \\
\hline$\%$ received maximum $\mathrm{RP}$ & 100 & 56 & male higher \\
\hline age at start of victimisation (yrs) & 12.0 & 11.7 & \\
\hline range (yrs) & 10.0 to 15.0 & 9.6 to 15.3 & \\
\hline$\%$ under 16 & 100 & 100 & \\
\hline duration on-going (yrs) & 2.4 & 2.3 & \\
\hline range (yrs) & 0.7 to 4.3 & 0.2 to 4.8 & \\
\hline VO relationship: family or relatives (\%) & 22 & 22 & \\
\hline well-known or known & 78 & 78 & \\
\hline \% case had court conviction & 89 & 89 & \\
\hline
\end{tabular}

*Difference noted when a 90\% confidence interval around the mean does not contain zero, or Fisher's Exact Test is significant at $p<.10$. 